\title{
Iraq Healthcare System before Covid-19 Pandemic
}

\author{
Aamir Jalal Al-Mosawi \\ Advisor doctor and expert trainer, The National Training and Development Center of the Iraqi \\ Ministry of Health, Baghdad, Iraq \\ *Corresponding Author: Aamir Jalal Al-Mosawi, Advisor doctor and expert trainer, The National \\ Training and Development Center of the Iraqi Ministry of Health, Baghdad, Iraq
}

\begin{abstract}
Background: Healthcare systems throughout the world are witnessing improvements that have been attributed to explosion in knowledge and introduction of innovations. However, our previous two descriptions of the Iraq health care system showed that the Iraq healthcare system was not witnessing worth mentioning improvement, but experiencing failures that have been attributed to corruption and lack of real leadership .The aim of this paper is to provide an updated description of the healthcare system before covid19 based on the most recently available unpublished data.
\end{abstract}

Materials and Methods: More recently available unpublished information about healthcare system in Iraq were identified and reviewed. There were more than 100 relevant unpublished information documents including official reports and documents of the Iraqi Ministry of Health and Iraqi Ministry of Planning. In addition, recently available relevant useful information available at internet web sites. The obtainable data were classified into the following categories: Demographic data relevant to healthcare, data about the organizational structure of the healthcare system, the national healthcare policies including national healthcare mission, vision, strategic goals and plans, data healthcare system financing, data about healthcare services delivery, data about the workforce in the Iraq healthcare system, data about maternal and child health, data about infectious diseases, information about chronic disorders and main causes of morbidity and mortality, information about medical education and healthcare education, data about professional training and development, and data about leadership in healthcare. Some relevant healthcare information for three provinces (The Kurdish provinces in the north of Iraq) of the eighteen provinces in Iraq was not available in English or Arabic.

Results: Iraq has been witnessing a noticeable growth in population from 35,095,772 in 2013 to an estimated population of 39127889 in 2019. However, the organizational structure of the Iraq health system, the backbone of the Iraq healthcare system witnessed no important change from the latest published description. The declared mission and vision of the Iraqi Ministry of Health have been updated by rephrasing. The total governmental budget allocation for the Iraqi Ministry of Health (excluding the budget of the Ministry of Health in Kurdistan) was 6.306,218, 000 Iraqi Dinnars in 2019. The total number of physicians increased from 30913 in 2013 to 34907 in 2018. Neonatal cardiopulmonary disorders collectively the most common cause of death in 2018. Chicken pox was the infectious disease reported to the Iraqi Ministry of Health and it occurred in 8 per 10000 population in 2019. Acute upper respiratory tract infections including tonsilopharyngitis collectively was the most common cause of outpatient morbidity registered by the Iraqi Ministry of Health in 2018. Digestive disorders including gall bladder, biliary and pancreatic disorders collectively was the most common cause of morbidity leading to hospitalization as registered by the Iraqi Ministry of Health in 2018. The total number of deaths during the year 2019 was 140621, and ischemic heart disease was the most common cause of death during the years 2018 and 2019. A large number of reports and documents showed that in Iraq, corruption including scientific professional, and academic corruption not only resulted in loss of the financial allocations for the health sector, but also resulted in loss of leadership in healthcare, undergraduate and postgraduate medical education.

Conclusion: Iraq health care system is not expected to experience worth mentioning improvement as long as there is no evidence of any serious intention of making real reforms.

Keywords: Healthcare system, corruption, leadership failure, Iraq.

\section{INTRODUCTION}

Healthcare systems throughout the world are witnessing improvements that have been attributed to explosion in knowledge and introduction of innovations. However, our previous two descriptions of the Iraq health care system showed that the Iraq healthcare system was not witnessing worth mentioning improvement, but experiencing failures that 
have been attributed to corruption and lack of real leadership [1, 2, 3, 4].The aim of this paper is to provide an updated description of the healthcare system before covid-19 based on the most recently available unpublished data.

\section{Materials ANd Methods}

More recently available unpublished information about healthcare system in Iraq were identified and reviewed. There were more than 100 relevant unpublished information documents including official reports and documents of the Iraqi Ministry of Health and Iraqi Ministry of Planning. In addition, recently available relevant useful information available at internet web sites. The obtainable data were classified into the following categories: Demographic data relevant to healthcare, data about the organizational structure of the healthcare system, the national healthcare policies including national healthcare mission, vision, strategic goals and plans, data healthcare system financing, data about healthcare services delivery, data about the workforce in the Iraq healthcare system, data about maternal and child health, data about infectious diseases, information about chronic disorders and main causes of morbidity and mortality, information about medical education and healthcare education, data about professional training and development, and data about leadership in healthcare. Some relevant healthcare information for three provinces (The Kurdish provinces in the north of Iraq) of the eighteen provinces in Iraq was not available in English or Arabic.

\section{RESULTS}

\section{Demographic Information Relevant to Healthcare}

According to the latest report of the Iraqi Ministry of planning which was available during the 2019, the total population of Iraq was estimated at 39127889 ( $50.5 \%$ males and $29.5 \%$ females). It was estimated that $69.8 \%$ of the population was living in urban regions, and $30 \%$ of the population was living in rural areas. $45.5 \%$ of the total Iraq population was estimated to be under the age of fifteen years. $54 \% \%$ of the total Iraq population was estimated to be between the ages of fifteen and sixty years, and only $5 \%$ of the population was above the age of sixty years.

\section{Organizational Structure of the Iraq Health System}

The organizational structure of the Iraq health system, the backbone of the Iraq healthcare system witnessed no important change from the latest published description [3].

\section{Information Related to National Healthcare} Policies

Many of the claimed national health policies in the Iraqi healthcare system have been included in articles 30, 31, 32, and 33 of the constitution and witnessed no change. However, recently there has been increasing public criticism for the whole constitution of the country and serious demands for writing a new constitution [1, 2, 3, 4]. The declared mission and vision of the Iraqi Ministry of Health have been updated by rephrasing. The previously published mission of the Iraqi Ministry of Health in 2013 stated "The Ministry of Health works to ensure the availability of integrated and complete healthcare to all society members in highest level of quality, through the investment in compliance with the professional ethics and society values, which is to achieve sustainable health development and to reduce morbidity and mortality" [3]. The claimed mission of the Iraqi Ministry of Health in 2018 stated "The Ministry of Health works to provide comprehensive health care to all members of the society and at the highest level of quality and to invest efficiently available resources in accordance with ethics of the profession and values of the society to ensure sustainable health development to reduce mortality and morbidly with participation of stakeholders".

A general vision statement for the years 20132017 stated "A society that is physically, mentally, and socially healthy", similarly a general vision statement for the years 20182020 has been introduced "Physically, psychologically, and socially healthy society" .Prolonged redundant, and mostly impractical list of nineteen strategic objectives have been claimed in 2013.

\section{Information Related to Healthcare System} Financing

The Iraqi Ministry of Health remained largely funded centrally by the government. The total governmental budget allocation for the Iraqi Ministry of Health (excluding the budget of the Ministry of Health in Kurdistan) was reduced from 7,360,552,000,000 Iraqi Dinnars (about 61.337 .933 .333 USD) in 2013 to $4,302,670,786,000$ Iraqi Dinnars in 2018. The total governmental budget allocation for the Iraqi Ministry of Health (excluding the budget of the Ministry of Health in Kurdistan) was 6.306,218, 000 Iraqi Dinnars in 2019. 
Information about Healthcare Services Delivery

The health services are delivered through hospitals, primary health centers and public health clinics $[1,2,3,4]$

In 2013, there were 2642 primary health care centers in Iraq, 1313 of them were managed by physicians while 1329 centers were managed other healthcare professionals. It was estimated that there was 0.8 primary health care centers for each 10000 population [3].

In 2018, there were 2765 primary health care centers in Iraq, $1111(40.2 \%)$ of them were managed by physicians while 1654 (59.8\%) centers were managed other healthcare professionals. It was estimated that there was 0.7 primary health care centers for each 10000 population.
In 2013, there were 255 governmental hospitals with 44997 beds and a bed occupancy rate of $50 \%$, and 105 private hospitals in all Iraq. 67 of the governmental hospitals were considered teaching hospitals. It was estimated that there was 0.7 hospitals for each 100000 population [3].

In 2018, the total number of governmental hospitals and specialized centers with inpatient services was 281 . The total number of beds available in governmental hospitals was estimated at 45300 beds with a bed occupancy rate of $57.2 \%$. There were 3609 incubators for neonate. The total number of hospitalized patients during the year 2018 was 2,902,440, and the estimated mortality rate was 18.1 for each 1000 hospitalized patients.The number of private non-governmental hospitals in 2018 was 135. Figure- 1 shows the main types of hospitals in Iraq in 2018.

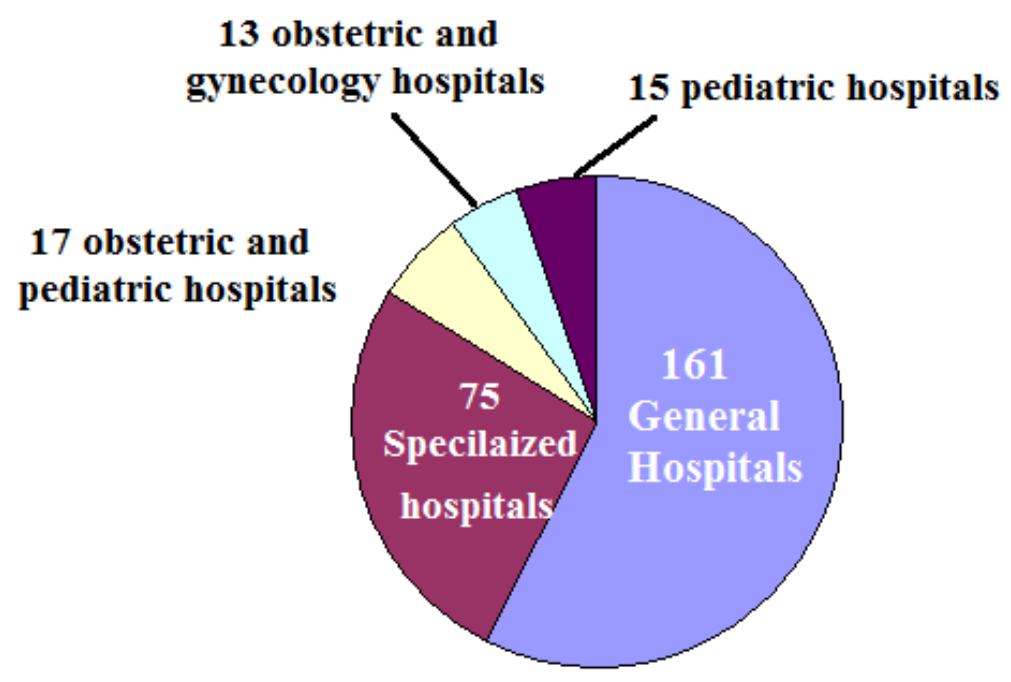

Figure1. The main types of governmental hospitals in Iraq in 2018

\section{Information about the Workforce in the Iraq Healthcare System}

In 2018, the total workforce in Iraq healthcare system was $302,994 \quad(171,736$ males and 131,258 females) including 34907 physicians (19174 males and 155660 females), 11997 dentists (5191 males 6806 and females), 12522 pharmacists (4806 males and 7716 females), 78588 nursing staff (38107 males and 40481 females), 73876 paramedical staff (44149 males and 29727 females), and 10812 laboratory staff (5015 males and 5797 females). It was estimated that there were 9.1 doctors, 3.1 dentists, 3.3 pharmacists, and 20.6 nursing staff for each 10000 of population.

\section{Information Related to Maternal and Child Health}

During the year 2019, it was estimated that the total number of births (Live births and stillborns) inside and outside Iraq was 1143192 , including $99.3 \%$ live births.

$42.2 \%$ of the births had a birth weight of 2.5 kilograms or higher. $8.7 \%$ of the births had a birth weight below 2.5 kilograms, while the weight was not recorded in $1.4 \%$ of the births during the year 2019. $67.3 \%$ of the births during the year 2019 occurred in governmental hospitals, $15.7 \%$ occurred in private hospitals, and $0.2 \%$ occurred in heath centers. While $15.9 \%$ of the births occurred outside medical 
and health institutions. $64 \%$ of the births were achieved by vaginal delivery, and $36 \%$ were achieved by cesarean section.

During the year 2019, congenital malformations were reported in 3.6 per 1000 births. Table-1 shows the percentage of the main types of Table1. The percentage of the main types of congenital malformations

\begin{tabular}{|l|c|c|c|}
\hline & Disorder & $\mathbf{2 0 1 8}$ & $\mathbf{2 0 1 9}$ \\
\hline $\mathbf{1}$ & Congenital malformations of the heart and circulatory system & $18.8 \%$ & $22.29 \%$ \\
\hline $\mathbf{2}$ & Congenital hydrocephalus & $10.21 \%$ & $7.69 \%$ \\
\hline $\mathbf{3}$ & Congenital malformations of the gastrointestinal tract & $7.21 \%$ & $6.69 \%$ \\
\hline $\mathbf{4}$ & Anencephaly and similar malformations & $5.37 \%$ & $6.49 \%$ \\
\hline $\mathbf{5}$ & Congenital malformations of the brain and spinal cord & $6.03 \%$ & $5.77 \%$ \\
\hline $\mathbf{6}$ & Congenital malformations of the lower limbs & $4.87 \%$ & $5.57 \%$ \\
\hline $\mathbf{7}$ & Down syndrome & $\mathrm{N} / \mathrm{A}$ & $3.29 \%$ \\
\hline $\mathbf{8}$ & Congenital malformations of the upper limbs & $3.23 \%$ & $2.95 \%$ \\
\hline $\mathbf{9}$ & Cleft lip and cleft palate & $2.73 \%$ & $2.73 \%$ \\
\hline $\mathbf{1 0}$ & Microcephaly & $2.9 \%$ & N/A \\
\hline
\end{tabular}

Acute diarrheal illnesses in children under the age of five years as reported by primary healthcare centers occurred in $4.9 \%$ during the year 2019, and 5.3\% during the year 2018 . $17.9 \%$ of the affected children receive antibiotics during the year 2019 , and $20.3 \%$ during the year 2018.

Lower respiratory infections (Pneumonia) in children under the age of five years as reported by primary healthcare centers occurred in $0.74 \%$ during the year 2019 and $0.8 \%$ during the year 2018. Table- 2 shows the main causes of neonatal deaths as registered the Iraqi Ministry of Health in 2018 congenital malformations reported during the $37 \%$ of infants fewer than six months were reported to have breast feeding during the year 2019, and 39\% during the year 2018.

Table2. The main causes of neonatal deaths as registered the Iraqi Ministry of Health in 2018 (The region of Kurdistan was not included)

\begin{tabular}{|c|l|c|}
\hline & Disorder & Percentage \\
\hline $\mathbf{1}$ & Neonatal respiratory disorders & $35.6 . \%$ \\
\hline $\mathbf{2}$ & Congenital malformations & $10.2 \%$ \\
\hline $\mathbf{3}$ & Infections including congenital, early neonatal infections, and pneumonias & $9.8 \%$ \\
\hline $\mathbf{4}$ & Deaths related to prematurity, postmaturity, and intra-uterine growth retardation & $6.2 \%$ \\
\hline $\mathbf{5}$ & Cardiovascular disorders & $1 \%$ \\
\hline $\mathbf{6}$ & Hemorrhagic and hematological disorders of the fetus and newborn & $0.6 \%$ \\
\hline
\end{tabular}

During the year 2019, the Iraqi Ministry of Information about Infectious Diseases

Health reported that 155159 women were using a family planning service compared to 85728 women in 2018.

Table3. The incidence of some infectious diseases per 10000 population as reported to the Iraqi Ministry of Health

\begin{tabular}{|l|c|c|}
\hline & $\mathbf{2 0 1 8}$ & $\mathbf{2 0 1 9}$ \\
\hline Kala azar & 0.07 & 0.04 \\
\hline Cutaneous leishmaniasis & 3 & 1.6 \\
\hline Infective hepatitis type A & 2.07 & 0.7 \\
\hline Infective hepatitis type B & 0.52 & 0.36 \\
\hline Infective hepatitis type C & 0.15 & 0.1 \\
\hline Infective hepatitis type E & 0.018 & 0.002 \\
\hline Measles & 1.13 & 0.83 \\
\hline Mumps & 4.55 & 8 \\
\hline Chicken pox & 11.92 & 0.2 \\
\hline Pertussis & 0.26 & 0 \\
\hline Diphtheria & 0.0005 & 0.0005 (3 cases reported $)$ \\
\hline Cholera & $0.0008(3$ cases reported $)$ & $0.3(1019$ cases reported $)$ \\
\hline Brucellosis & $0.21(798$ cases reported $)$ & $0.29(1120$ cases reported $)$ \\
\hline Typhoid Fever & 0.18 & \\
\hline
\end{tabular}

Table-3 shows the incidence of some infectious diseases per 10000 population as registered by the Iraqi Ministry of Health 
Information about Chronic Disorders and Main Causes of Morbidity and Mortality

Table-4 shows the main causes of outpatient morbidity registered by the Iraqi Ministry of Table4. The main causes of outpatient morbidity registered by the Iraqi Ministry of Health in 2018 (The region of Kurdistan was not included)

\begin{tabular}{|c|l|c|}
\hline & Disorder & Percentage \\
\hline $\mathbf{1}$ & Acute upper respiratory tract infections including tonsilopharyngitis & $12.7 \%$ \\
\hline $\mathbf{2}$ & Acute bronchitis and bronchiolitis & $5 \%$ \\
\hline $\mathbf{3}$ & Urinary tract disorders & $3.2 \%$ \\
\hline $\mathbf{4}$ & Hypertension & $2.9 \%$ \\
\hline $\mathbf{5}$ & Infective diarrheas and gastroenteritis & $2.8 \%$ \\
\hline $\mathbf{6}$ & Influenzal illnesses & $2.7 \%$ \\
\hline $\mathbf{7}$ & Dental disorders including caries & $2.5 \%$ \\
\hline $\mathbf{8}$ & Diabetes mellitus & $2.1 \%$ \\
\hline
\end{tabular}

Table5. The main causes of morbidity leading to hospitalization as registered by the Iraqi Ministry of Health in 2018 (The region of Kurdistan was not included)

\begin{tabular}{|l|l|c|}
\hline & Disorder & $\mathbf{\%}$ \\
\hline $\mathbf{1}$ & Digestive disorders including gall bladder, biliary \& pancreatic disorders & $10.5 \%$ \\
\hline $\mathbf{2}$ & Respiratory disorders & $8.5 \%$ \\
\hline $\mathbf{3}$ & $\begin{array}{l}\text { Disorders of the circulatory system including ischemic heart disease \& cerebro-vascular } \\
\text { disorders }\end{array}$ & $7.1 \%$ \\
\hline $\mathbf{4}$ & Genitourinary disorders including renal failure & $6.1 \%$ \\
\hline $\mathbf{5}$ & Neonatal disorders & $5.5 \%$ \\
\hline $\mathbf{6}$ & Infectious and parasitic disorders & $4.8 \%$ \\
\hline $\mathbf{7}$ & Injuries and poisonings & $4.3 \%$ \\
\hline $\mathbf{8}$ & Malignancies & $3.1 \%$ \\
\hline $\mathbf{9}$ & Ocular & $2.4 \%$ \\
\hline $\mathbf{1 0}$ & Hematological & $2.2 \%$ \\
\hline
\end{tabular}

The total number of deaths during the year 2019 was 140621 . Table- 6 shows the main causes of mortality during the years 2018 and 2019 . Table- 7 shows the of main causes of mortality between the ages of 10 to 19 years during the year 2019 .

Table6. The main causes of mortality $(2018,2019)$

\begin{tabular}{|c|c|c|c|}
\hline & Disorder & 2018 & 2019 \\
\hline 1 & Ischemic heart disease & $12.06 \%$ & $12.03 \%$ \\
\hline 2 & Cancer & $9.43 \%$ & $9.33 \%$ \\
\hline 3 & Cerebro-vascular disorders & $10.36 \%$ & $8.4 \%$ \\
\hline 4 & Hypertensive disease & $6.7 \%$ & $6.8 \%$ \\
\hline 5 & Non-ischemic heart disease & $7.37 \%$ & $5.9 \%$ \\
\hline 6 & Renal failure & $5.85 \%$ & $5.3 \%$ \\
\hline 7 & Road Traffic accidents & $4.57 \%$ & $4.9 \%$ \\
\hline 8 & Diabetes mellitus & $4.19 \%$ & $4.8 \%$ \\
\hline 9 & Neonatal cardiopulmonary disorders & $3.89 \%$ & $4.1 \%$ \\
\hline 10 & Sepsis and infective disorders & N/A & $2.6 \%$ \\
\hline
\end{tabular}

Table7. The main causes of mortality between the ages of 10 to 19 years during the year 2019

\begin{tabular}{|l|l|l|}
\hline & Disorder & $\mathbf{2 0 1 9}$ \\
\hline $\mathbf{1}$ & Accidents & $13.8 \%$ \\
\hline $\mathbf{2}$ & Cerebral palsy and other neurological disabling conditions & $10.5 \%$ \\
\hline $\mathbf{3}$ & Heart disease & $8.3 \%$ \\
\hline $\mathbf{4}$ & Malignancy & $7.9 \%$ \\
\hline $\mathbf{5}$ & Renal failure & $5.2 \%$ \\
\hline $\mathbf{6}$ & Pulmonary infections and influenza & $4.9 \%$ \\
\hline $\mathbf{7}$ & Cerebro-vascular disorders & $4.2 \%$ \\
\hline $\mathbf{8}$ & Sepsis and infective disorders & $3.8 \%$ \\
\hline $\mathbf{9}$ & Ischemic heart disease & $3.2 \%$ \\
\hline $\mathbf{1 0}$ & Respiratory disorders & $2.5 \%$ \\
\hline
\end{tabular}


Information about Medical Education and Healthcare Education

During the year 2019, there were 29 governmental and 2 private colleges of medicine, 22 governmental and 31 private colleges of dentistry, 20 governmental and 25 private colleges of pharmacy, 16 governmental and 13 private colleges of nursing, 10 governmental and 53 private health technical colleges, 28 governmental institutes, 57 governmental nursing, and 19 midwifery schools (Equivalent to ordinary secondary schools).

Information about Professional Training and Development

Many reports and documents showed that despite the claims of conducting a large number of training courses for doctors and other healthcare professionals and workers, the vast majority of these course were not accredited and were mostly conducted by unqualified personnel.

\section{Information about Leadership in Healthcare}

A large number of reports and documents showed that in Iraq, corruption including scientific professional, and academic corruption not only resulted in loss of the financial allocations for the health sector, but also resulted in loss of leadership in healthcare, undergraduate and postgraduate medical education. Heads of clinical departments in hospitals, heads of academics departments in medical colleges, teaching hospital directors, general directors of health directorates, deans of medical school, and heads of boards of medical specializations have been appointed in most instances regardless of their professional and scientific qualifications.
Many documents showed that corrupt laws and legislation, over many years gradually destroyed the infrastructure of healthcare organization and medical education institution including medical colleges and disrupted the healthy hierarchy of these organization. The people ruling the country issued laws and regulations aiming at enabling their followers to take the highest rank professional and academic positions and receive high salaries and pensions regardless of their qualifications, and regardless of the fact that such thing leads to loss of the associated leadership merits of these positions. These position are called "The special degrees" which include the ministers' minister deputies and general directors, presidents of universities, deans of colleges including medical colleges.

Many documents showed that these positions "The special degrees or ranks" are not political and should not have been controlled by people ruling the country.

\section{DISCUSSION}

The organizational structure of the Iraq health system witnessed no important change from the latest description [3]. The Iraqi Ministry of health remains the backbone of the health system in Iraq and the main health care provider. Private medical sector also exist and other agencies such as the Red Crescent also contribute to the health services. Therefore, the major components of health system infrastructure of Iraq are directed by the Iraqi Ministry of Health. Figure-2 shows a simplification of the National Iraqi Health systems.

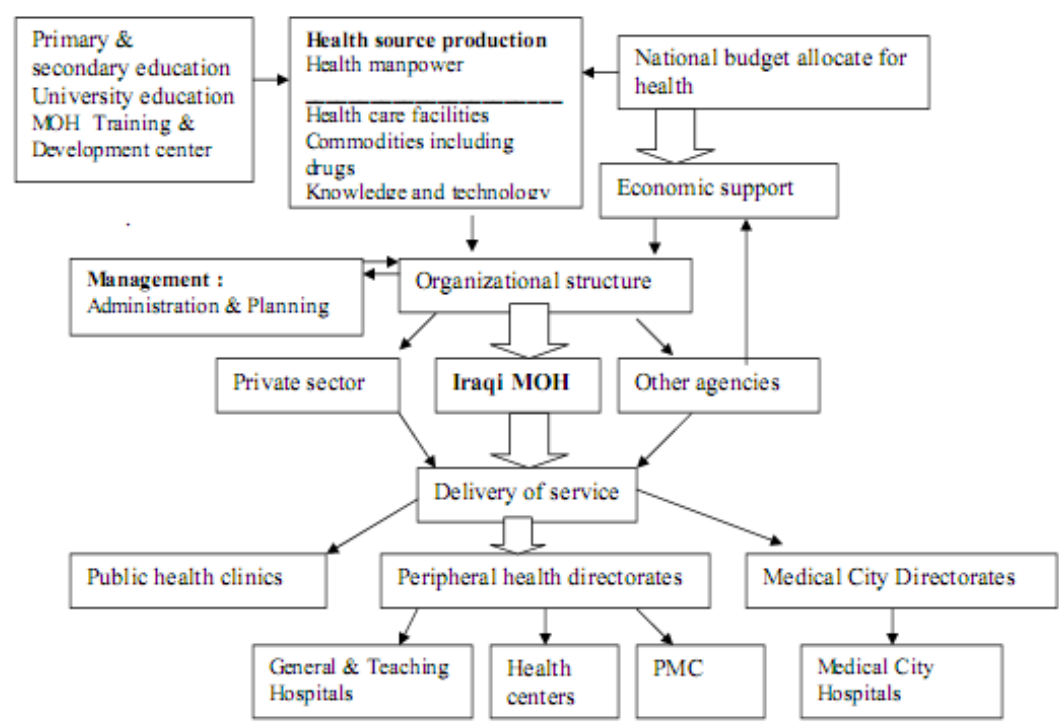

Figure2. A simplification of the National Iraqi Health systems (The New Iraqi Journal of Medicine kindly gave us the permission to publish this figure). MOH (Ministry of Health), PMC (Primary care medical centers). 
Table- 8 shows the current structure of the Iraqi Ministry of Health. The administrative structure of the peripheral directorates is similar to the structure of the Iraqi Ministry of Health. Hospitals (General and teaching), primary health care clinics and health centers are affiliated with peripheral health directorates. The health directorates of 3 northern provinces (Sulaimanyia, Erbil, and Dohouk) affiliated with Ministry of Health the Kurdistan.

Table8. The current structure of the Iraqi Ministry of Health (The New Iraqi Journal of Medicine kindly gave us the permission to publish this table) with minor medications

\footnotetext{
Headquarter

1-Higher Offices of the minister, and two deputies

2-Directorate of planning and human resources development:

Department of Health policies and strategic planning

Department of Health information technologies

Department of Manpower and higher education

Nursing affairs

Department of Health economic and financial planning

3-Directorate of administration, legal and financial affairs.

4-Directorates of projects and engineering services

5-Directorate of Technical affairs

6-Directorate of Medical operations and special services

7-Directorate of public health and primary health care

8-Kimadia the state company for drug marketing

9-Directorate of Medical City

10-Training and development center

Public health clinics

Peripheral health directorate
}

During the year 2013, 8883 (4376 males and 4507 females) cases of tuberculosis were reported to Iraqi Ministry of Health including 5360 had pulmonary tuberculosis and 3523 had extra-pulmonary tuberculosis [3]. However, we couldn't find recent data about the reported cases of tuberculosis during the years 2018 and 2019.

During the year 2013, 1572 cases (912 males and 660 females) of various types of meningitis, 1267 cases (23 males and 1244 females) of toxoplasmosis, 881 cases (323 males and 858 females) of hydatid cyst, 545 cases (284 males and 261 females) of bacillary dysentery, 402 cases (225 males and 177 females) of acute flaccid paralysis, and 30 cases ( 21 males and 9 females) of German measles, 20 cases (15 males and 5 females) of Acquired immune deficiency syndrome [one of them died during the same year], and 8 cases of rabies ( 7 males and 1 female), were reported to Iraqi Ministry of Health [2013]. However, we also couldn't find recent data about the reported cases of the infections during the years 2018 and 2019.

Many publications have recently reported that medical education in Iraq has been increasingly criticized for not meeting the acceptable international standards and not achieving acceptable positions in the international ranking of medical colleges. Deterioration in medical education has been attributed to the lack of academic leadership resulting from the fact that for decades, heads of clinical departments in hospitals, heads of academics departments in medical colleges, deans of medical school, and heads of boards of medical specializations have been appointed in most instances regardless of their professional and scientific qualifications $[5,6.7]$.

However, few courses including medical and healthcare leadership courses, training of trainers (TOT) courses, pediatric psychiatry courses, and advanced English language courses had international accreditation and their scientific contents and training methodologies were published in academic books[3, $8,9,10,11,12,13]$.

It is a matter of fact that the majority of challenges in developing world in the field of healthcare are mostly attributed to the lack of financial resources necessary for the production of adequate number of qualified doctors to face the challenges of the provision of the health services. The lack of financial resources also 
lead to shortage in the diagnostic equipments, preventive interventions and medicines necessary to deal with emerging challenges in healthcare $[3,4,8]$. However, in Iraq the majority of challenges in the field of healthcare are mostly attributed to corruption including scientific professional and academic corruption, they resulted not only in loss of the financial allocations for the health sector, but also resulted in loss of leadership in healthcare, undergraduate and postgraduate medical education.

\section{CONCLUSION}

Iraq health care system is not expected to experience worth mentioning improvement as long as there is no evidence of any serious intention of making real reforms.

\section{ACKNOWLEDGEMENT}

The New Iraqi Journal of Medicine kindly gave us the permission to publish figure-2, and table-8.

\section{REFERENCES}

[1] Al-Hasnawi S, Amir Al khuzaie A, Al-Mosawi AJ. Iraq health care system: An overview. The N Iraqi J Med 2009; 5(3):5-13.

[2] Al-Mosawi AJ. Healthcare system in Iraq .1 $1^{\text {st }}$ ed., Saarbrücken; LAP Lambert Academic Publishing: 2014 (ISBN: 978-3-659-555336).Ameen MH, Al Mosawi AJ, Anoze A. The evolution of modern healthcare and health education in Iraq. The N Iraqi J Med 2011; 7(1):72-80.

[3] Al-Mosawi AJ. Iraq healthcare system: An update. Lupine Online Journal of Medical Sciences (ISSN: 2641-1725) 2020; 4(3):404411. DOI: 10.32474/LOJMS.2020.04.000190
[4] Al-Mosawi AJ. Healthcare system in Iraq .1 ${ }^{\text {st }}$ ed., Saarbrücken; LAP Lambert Academic Publishing: 2014 (ISBN: 978-3-659-55533-6).

[5] Al-Mosawi AJ. Academic Medical Leadership: An overview of the emerging concepts and ideas. Clinical medical reviews and reports 2020; 2(3):1-3. Doi: 10.31579/ cmrr. 20 20/014

[6] Al-Mosawi AJ. A Corrected H-Index for Academic Leadership Determination: A Bibliographic Research. Archives of Health Science (ISSN 2641-7456) 2020; 4 (1):1-7. Doi: 10.31829/2641-7456/ahs2020-4 (1)-119

[7] Al-Mosawi AJ. A corrected H-index for academic leadership determination..$^{\text {st }}$ ed., Saarbrücken; LAP Lambert Academic Publishing: 2020 (ISBN: 978-620-2-67787-5).

[8] Al-Mosawi AJ. Medical and Healthcare leadership: A training course. $1^{\text {st }}$ ed., Saarbrücken; LAP Lambert Academic Publishing: 2016 (ISBN: 978-3-659-85373-9).

[9] Al-Mosawi AJ. Leadership in Medicine and Healthcare: An accredited training course. $1^{\text {st }}$ ed., Saarbrücken; LAP Lambert Academic Publishing: 2017 (ISBN: 978-3-659-92501-6).

[10] Al-Mosawi AJ. An accredited training of the trainers (TOT) training course. $1^{\text {st }}$ ed., Saarbrücken; LAP Lambert Academic Publishing: 2017 (ISBN: 978-3-659-88198-5).

[11] Al-Mosawi AJ. An introduction to advanced English learning. $1^{\text {st }}$ ed., Saarbrücken; LAP Lambert Academic Publishing: 2013 (ISBN: 978-3-659-49748-3).

[12] Al-Mosawi AJ. Pediatric psychiatry: An accredited training course. $1^{\text {st }}$ ed., Saarbrücken; LAP Lambert Academic Publishing: 2018 (ISBN: 978-613-9-86510-9).

[13] Al-Mosawi AJ. Advanced medical leadership course: A practical textbook for trainers. Scholar's press: 2020 (ISBN-13:978-613-893835-4, ISBN-10:6138938356).

Citation: Aamir Jalal Al-Mosawi, "Iraq Healthcare System before Covid-19 Pandemic", International Journal of Research Studies in Medical and Health Sciences. 2020; 5(12): 16-23.

Copyright: ( 2020 Aamir Jalal Al-Mosawi, This is an open-access article distributed under the terms of the Creative Commons Attribution License, which permits unrestricted use, distribution, and reproduction in any medium, provided the original author and source are credited. 